\title{
Mediação pedagógica na educação a distância: as pesquisas brasileiras
}

\author{
Lêda Gonçalves de Freitas \\ Carlos Ângelo de Meneses Sousa \\ Universidade Católica de Brasília
}

\section{Resumo}

Trata-se de uma pesquisa exploratória realizada nos Bancos de Teses da Capes, na Biblioteca Digital Brasileira de Teses e Dissertações, no SciELO Brasil e no Google Acadêmico sobre mediação pedagógica em EaD. Verificou-se o destaque a duas perspectivas complementares - a do papel do professor-tutor e a de sua articulação com os artefatos tecnológicos -, que ressaltam a importância da mediação pedagógica nos processos de educação a distância e apontam elementos didático-pedagógicos que precisam ser efetivamente inseridos pelos diversos sistemas de EaD. Assim, cabe assegurar práticas consistentes de mediação pedagógica em que a ação docente mobilize a capacidade do estudante de aprender a aprender.

Palavras-chave: pedagógica. Educação a distância. Ensino-aprendizagem. 


\section{Educational mediation in distance education: Brazilian research}

The article refers to exploratory research conducted in Capes' thesis banks, in the Brazilian Digital Library of Thesis and Dissertations, in SciELO Brasil and in Academic Google, on educational mediation in distance education. Two complementary perspectives stood out - the role of the professor-tutor and its relation with technological artifacts. They highlight the importance of educational mediation in distance education processes and point to didactical-educational elements that must be effectively included by the several distance education systems. Thus, one must assure consistent practices of educational mediation in which the teachers' work mobilizes the students' capacity to learn how to learn.

Keywords: Educational mediation. Distance Education. Teaching/learning.

\section{Mediación pedagógica en la educación a distancia: las investigaciones brasileñas}

Consiste en una encuesta realizada en la base de datos de Tesis Capes en la Biblioteca Digital Brasileña de Tesis y Disertaciones, SciELO Brasil y Google Scholar sobre la mediación pedagógica em educación a distancia (EAD). Se encontró dos perspectivas complementares: el papel del profesor-tutor y su articulación con los artefactos tecnológicos. Diversos estudios no sólo ponen de relieve la importancia de los procesos de mediación pedagógica en EAD, pero el punto didáctico-pedagógicos elementos que deben ser colocados por muchos sistemas de EAD. Hay que tener prácticas coherentes de mediación pedagógica en la que la enseñanza de movilizar la capacidad del alumno para aprender a aprender.

Palabras-clave: Mediación Pedagógica. Educación a Distancia. Enseñanza-aprendizaje. 


\section{Introdução}

A proposta deste artigo é refletir sobre a mediação pedagógica na educação a distância ( $\mathrm{EaD})$, considerando os estudos nesta área. Consiste em uma pesquisa exploratória realizada no Banco de Teses da Capes, na Biblioteca Digital Brasileira de Teses e Dissertações (BDTD), nas bases de dados SciELO Brasil (Scientific Electronic Library Online) e no banco de dados Google Acadêmico. 0 propósito foi mostrar uma revisão do que tem sido publicado no Brasil sobre a temática, bem como provocar uma reflexão sobre como a mediação pedagógica na modalidade de educação a distância tem sido concebida, buscando estimular pesquisas no campo da didática na EaD.

Diante dos avanços tecnológicos, a educação a distância, uma modalidade de educação que exige a utilização de tecnologias para que o processo de ensinoaprendizagem ocorra, expande-se nos diversos níveis de ensino, em particular no ensino superior. A característica principal dessa modalidade de educação é a separação espacial e temporal entre professor e aluno. Mesmo não estando juntos, como é comum na educação presencial, alunos e professores se comunicam por meio das mais diversas tecnologias, ou seja, estão em contato mediados por tecnologias. É importante destacarmos a concepção de tecnologia que advogamos: nós a compreendemos, conforme Sousa (2011, p.171), “como uma objetivação das relações sociais que comanda e fecunda qualquer sociedade, não sendo esta autônoma e apartada daqueles que a geram, isto é, do próprio homem, da sociedade. A tecnologia é uma invenção humana".

0 olhar simmeliano sobre as relações sociais complementa a concepção de técnica acima mencionada. Simmel (2006, p.61) nos alerta que a técnica, as funções ou os resultados da inteligência não são, de maneira imediata, por si só sociais. Em suas palavras, "são fatores da sociação apenas quando transformam a mera agregação isolada dos indivíduos em determinadas formas de estar com o outro e de ser para o outro que pertencem ao conceito geral de interação". Este último conceito de interação é que consubstancia, para o nosso estudo, a técnica como meio de mediação pedagógica, bem como a transforma em sociação. Esta, na perspectiva simmeliana, é a maneira pela qual os indivíduos se agrupam, diferentemente e de diversas maneiras, em unidades que satisfazem seus interesses.

A mediação no presente artigo é compreendida sob o olhar da abordagem histórico-cultural que, em linhas gerais, concebe o sujeito como um ser ativo, cujas aprendizagens são construídas na interação com o objeto e com outros seres sociais. Assim, de acordo com Vygotsky (1994), o homem é um ser social que aprende na interação com os outros. Para tanto, há que se fazer uso da mediação, que se realiza pelo uso de instrumentos e signos. Estes são externos e construídos pelos homens, considerando as suas necessidades.

Vygotsky (1994) traz o conceito de Zona de Desenvolvimento Proximal (ZDP), que 
é a distância entre o nível de desenvolvimento real e o nível de desenvolvimento potencial. 0 desenvolvimento real se relaciona com a capacidade do sujeito para resolver sozinho determinados problemas; já o desenvolvimento potencial é determinado pelas possibilidades de os sujeitos solucionarem problemas por meio da orientação de outros sujeitos. Logo, diz respeito à série de conhecimentos que os sujeitos ainda não aprenderam, mas que têm potencial de aprender. Diante disso, a ZDP é uma ampla janela de oportunidade para a aprendizagem, sendo necessária, portanto, a partir da abordagem histórico-cultural, a ação mediadora do professor com vistas a preparar e conceber estratégias de ensino para potencializar a aprendizagem dos sujeitos.

A mediação se efetiva pela ação do outro mais experiente. Para esta reflexão, é o professor-tutor que possibilita uma ação significativa entre os sujeitos aprendizes e o objeto do conhecimento para que estes internalizem conceitos. Deste modo, é a mediação que propicia a aprendizagem.

A mediação pedagógica, por conseguinte, tem a ver com a ação do professor que, conforme Masetto (2008), deve ser um incentivador e motivador da aprendizagem dos estudantes. Na EaD, especialmente, esse processo é desenvolvido utilizandose de vários meios, sobretudo das novas tecnologias. Cabe aqui destacar que todo processo de mediação não ocorre autonomamente ou isoladamente, pois, segundo Freire (2005, p.64), "o pensar do educador somente ganha autenticidade na autenticidade do pensar dos educandos, mediatizados ambos pela realidade, portanto, na intercomunicação". Sendo assim, a mediação pedagógica que defendemos é de natureza dialógica, no sentido freiriano.

Uma das centralidades do ato educativo é a interação. Educar é interagir, dialogar. A educação a distância, pelas suas particularidades, mas não menos que a educação presencial, tem como desafio a superação da distância e fazer-se presente na efetividade da interação. Nesse sentido, hoje mais do que em outros tempos, a nossa sociedade alarga e apresenta, pela mediação das tecnologias, especialmente das novas tecnologias, possibilidades de mais e melhor interação. Indubitavelmente, como toda realidade criada pelo homem, a marca da ambiguidade se faz presente; isto é, assim como tais aparatos podem ensejar diálogo, interação, eles podem também, segundo o ideário de sua constituição e/ou utilização, tornar a presença uma distância, especialmente quando não houver uma consideração ao outro em sua alteridade.

A EaD tem vivenciado várias fases, desde a primeira etapa com o ensino por correspondência; em seguida, com a fase da transmissão radiofônica e televisiva; e, mais recentemente, com a utilização da informática conjugada à comunicação - que gerou a telemática. Esta tem propiciado maior amplitude e diversificação dos programas de educação a distância, pois permite a interação quase presencial entre professores e alunos, por meio de bate-papos virtuais, videoconferências e teleconferências, entre outras ferramentas.

A expansão da EaD no Brasil, com o advento das modernas tecnologias, 
gerou um farto material de pesquisa sobre as potencialidades das mediações impulsionadas pelas tecnologias ante a separação espacial entre estudantes e professores. Por isto, cabe dar destaque à produção acadêmica no Brasil sobre a mediação pedagógica na educação a distância, visando ampliar e fortalecer a pesquisa em torno dos processos de ensino nesta modalidade de educação.

\section{A mediação pedagógica na educação a distância: as pesquisas brasileiras}

A seguir, destaca-se no Quadro 1 a relação de artigos que foram acessados e que trazem a temática da mediação pedagógica na EaD em seus títulos. Foram nove artigos publicados em periódicos diversos.

Quadro 1: Relação de artigos com a temática mediação pedagógica

\begin{tabular}{|l|l|l|}
\hline \multicolumn{1}{|c|}{ Título } & Ano & Periódico \\
\hline $\begin{array}{l}\text { A mediação pedagógica em propostas } \\
\text { de formação continuada de professo- } \\
\text { res em informática na educação }\end{array}$ & 2001 & Portal da ABED \\
\hline $\begin{array}{l}\text { Formação, mediação e prática peda- } \\
\text { gógica do tutor orientador em ambien- } \\
\text { tes virtuais construtivistas de apren- } \\
\text { dizagem }\end{array}$ & 2002 & Tecnologia Educacional \\
\hline $\begin{array}{l}\text { Medição digital e pedagógica } \\
\begin{array}{l}\text { A mediação pedagógica: suas relações } \\
\text { e interdependências }\end{array}\end{array}$ & 2006 & $\begin{array}{l}\text { Anais Simpósio Brasileiro de } \\
\text { Informática na Educação }\end{array}$ \\
\hline $\begin{array}{l}\text { Mediação pedagógica online: análise } \\
\text { transversal de ferramentas de intera- } \\
\text { ção }\end{array}$ & 2008 & $\begin{array}{l}\text { Colóquio Luso-Brasileiro so- } \\
\text { bre questões curriculares 4 }\end{array}$ \\
\hline $\begin{array}{l}\text { Mediação pedagógica em ambientes } \\
\text { virtuais de aprendizagem: a perspecti- } \\
\text { va dos alunos }\end{array}$ & 2009 & $\begin{array}{l}\text { Anais IX Congresso Nacional } \\
\text { de Educação - Educere }\end{array}$ \\
\hline $\begin{array}{l}\text { Performance docente na mediação } \\
\text { pedagógica em educação a distância }\end{array}$ & 2010 & Revista Inter Ação \\
\hline
\end{tabular}




\begin{tabular}{|l|l|l|}
\hline $\begin{array}{l}\text { Formação docente e mediação pe- } \\
\text { dagógica em cursos de licenciatura } \\
\text { a distância do sistema Universidade } \\
\text { Aberta do Brasil }\end{array}$ & 2010 & Revista Inter Ação \\
\hline $\begin{array}{l}\text { Mediação pedagógica em educação a } \\
\text { distância: inovação na docência uni- } \\
\text { versitária no processo de elaboração } \\
\text { de materiais didáticos }\end{array}$ & 2010 & $\begin{array}{l}\text { Revista Iberoamericana de Edu- } \\
\text { cación a Distancia }\end{array}$ \\
\hline
\end{tabular}

Fonte: Quadro elaborado pelos autores com base no SciELO Brasil e no Google Acadêmico.

Prado e Martins (2001) analisaram a mediação pedagógica em um curso para professores que trabalham com alunos com necessidades especiais. 0 curso foi desenvolvido no ambiente de aprendizagem TelEduc. Os autores consideram como elementos essenciais para a mediação pedagógica a ação do professore, no caso do curso estudado, o formador. Com efeito, asseveram que o formador na educação a distância deve ser capaz de orientar, facilitar, articular e instigar os estudantes para o processo de aprendizagem. Ademais, os autores destacam que o formador deve estar constantemente presente, acompanhando os estudantes nas diversas atividades para que intervenha com a finalidade de provocar a reflexão crítica e indagativa.

0 estudo de Santos e Rezende (2002) discute a função mediadora do tutororientador em cursos a distância na perspectiva construtivista. Os autores, fundamentados em Piaget e Vygotsky, entendem que a mediação pedagógica exercida pelo tutor-orientador, em curso realizado em ambiente virtual, presume o diálogo, a troca de experiências, o debate instigador, o apoio, a seleção e organização de informaç̃os, a construção da cooperação entre os participantes com vistas à construção ativa do conhecimento pelos estudantes. Ressalta-se que a mediação pedagógica deve buscar uma prática que supere o paradigma de aprendizagem empirista. Dessa forma, a ação do tutor-orientador deve ser a de incitar a troca entre os participantes nas diversas ferramentas de interação, a fim de possibilitar a aprendizagem num contexto de compartilhamento em que todos possam aprender com todos.

Alberto Sobrinho (2003) busca ressaltar as implicações entre a técnica e a pedagogia. Para tanto, ressalta a capacidade mediadora dos dispositivos técnicos nos processos de ensino e aprendizagem e os desafios da formação dos professores para realizar a mediação técnico-pedagógica. De maneira geral, ele acentua que, no contexto das novas tecnologias da informação e comunicação, os docentes necessitam articular os processos digitais na suas práticas mediadoras. Além de considerar os artefatos convencionais como os livros e outros dispositivos clássicos para realizar a função de ensinar, a internet e todos os artefatos da 
cultura tecnológica podem fomentar sobremaneira a prática de mediação dos professores.

O artigo de Prado (2006) trata da concepção de mediação pedagógica referenciada na inter-relação entre o processo de ensino e a aprendizagem. Considera que os materiais, as atividades e as interações são os elementos essenciais para a mediação pedagógica em ambientes virtuais. As informações transmitidas para os estudantes por meio dos materiais precisam ser transformadas em conhecimento. 0 material requer que o estudante consiga dar sentido à informação comunicada de forma que interprete, construa relações, faça comparações, analise, experimente e diferencie. Para isso, a autora menciona o papel das atividades nos cursos virtuais, as quais devem levar o estudante a reconhecer sua autoria em uma situação prática e contextualizada. As atividades se efetivam por meio das interações que os estudantes realizam no curso com os materiais, com o conhecimento a ser aprendido e com as pessoas. Em vista disso, o pesquisador releva que o essencial na mediação pedagógica é a articulação que o professor precisa assumir, a partir de uma postura reflexiva e investigativa, de modo que consiga criar estratégias significativas para a aprendizagem dos estudantes.

Rios, Pimentel e Silva (2008) apresentam uma discussão em torno das possibilidades de mediação pedagógica em fórum virtual no Ambiente Virtual de Aprendizagem (AVA) Moodle. A análise foi feita em um curso de especialização na área de educação. Os autores afirmam que o uso do fórum como recurso para a aprendizagem requer do professor-mediador uma mediação pedagógica amplamente participativa, disciplinada e criativa, como uma forma de assegurar o engajamento de todos no processo de ensino e aprendizagem com vistas à construção de um pensar coletivo. Assim, a mediação pedagógica deve buscar a autoria e coautoria dos participantes com a finalidade de garantir a construção do conhecimento.

0 artigo de Machado e Teruya (2009) traz uma reflexão sobre a importância da mediação pedagógica em cursos a distância em ambientes virtuais de aprendizagem, enfatizando a presença do tutor nos espaços virtuais. As autoras compreendem que a mediação pedagógica é uma intervenção no processo de aprender dos estudantes, seja na educação presencial, seja na virtual. $\mathrm{Na}$ educação a distância, a realização da mediação pelo professor se dá por meio dos signos e instrumentos que possibilitarão o aprendizado dos estudantes. A mediação pedagógica do tutor, consequentemente, abrange comentar as tarefas individuais dos estudantes, convidá-los para participar das discussões em grupo; ser um orientador e motivador, apresentando empatia e domínio dos conhecimentos trabalhados nos cursos. Nesse sentido, para Machado e Teruya, a mediação pedagógica deve se concretizar em instigar a participação, acompanhar as dúvidas dos estudantes e identificar as ausências ao longo do curso com vistas a minimizar a evasão.

Cruz (2010), em seu artigo, descreve os resultados de uma investigação sobre 
a mediação pedagógica no processo comunicacional em cursos a distância e sua relação com a formação docente para a EaD. A pesquisadora assevera que os fóruns utilizados como espaços comunicacionais não conseguiram dar conta das trocas de conhecimentos, uma vez que se tornaram respostas às perguntas dos tutores, faltando interações e articulações de ideias. Para a autora, os estudantes não foram incitados à reflexão e ao compartilhamento de conhecimentos. A autonomia, essencial para a EaD, deve ser trabalhada por meio de mediação pedagógica que busque a troca de experiências, o diálogo e as discussões. Diante disso, ela chama a atenção para a necessidade da formação continuada dos professores-tutores direcionada para desenvolver a capacidade de realizar a mediação pedagógica em cursos virtuais. Esta função necessita ser planejada e pensada com cuidado, para que os recursos dos ambientes virtuais não sejam subutilizados e o processo de ensino-aprendizagem, numa perspectiva de construção coletiva do conhecimento e da autonomia do estudante, seja potencializado.

Mallmann (2010) buscou em seu texto reunir as contribuições teóricometodológicas conseguidas com pesquisa sobre elaboração de materiais didáticos para mediação pedagógica em EaD. Ela considera que os materiais didáticos, na educação a distância, assumem um caráter fundamental de mediação pedagógica no processo de ensino-aprendizagem. Desse modo, os materiais didáticos, enquanto mediadores do ensino e da aprendizagem, devem suscitar ações, abstrações e construções dos conhecimentos. A autora destaca ainda que os materiais didáticos proporcionam o encontro entre professores, estudantes e 0 conhecimento num contexto de interações síncronas e assíncronas. Por ter um papel essencial na EaD, os materiais didáticos, diz a pesquisadora, precisam ser elaborados por uma equipe multidisciplinar, em que o planejamento é fundamental para garantir a qualidade do material. Neste sentido, os materiais didáticos precisam ser organizados de forma a produzirem ações e operações de ensinoaprendizagem.

Em outra produção acadêmica, Mallmann, em parceria com Catapan (2010), traz especificidades da ação docente na mediação pedagógica em EaD, a partir de uma revisão bibliográfica. As autoras mostram que a mediação pedagógica potencializa-se quando os sujeitos, sejam eles professores, tutores e estudantes, estão articulados com artefatos didático-pedagógicos limpressos e hipermidiáticos). Assim sendo, o processo de mediação pedagógica se realiza pela mobilização dos artefatos didáticos-pedagógicos pelos sujeitos do processo de ensino-aprendizagem, que propiciam a interação e a interatividade. Mallmann e Catapan (2010) compreendem que a mediação pedagógica envolve interação e interatividade entre os participantes de um determinado curso que se realiza por meio dos artefatos didático-pedagógicos impressos e hipermidiáticos. As especificidades da mediação pedagógica na EaD, segundo as autoras, estão na atuação do professor nesta modalidade de ensino, que abrange a seleção, elaboração, implementação, avaliação e reelaboração dos materiais didáticos. 
Para tanto, o docente precisa ter competência, desejo e autonomia, princípios que garantem autoria e coautoria no processo de mediação pedagógica na EaD.

Com base nos estudos apresentados, pode-se considerar que a mediação pedagógica na educação a distância tem sido estudada em duas perspectivas que se complementam: a do papel do professor-tutor e a da articulação entre a atuação do professor com os artefatos tecnológicos.

A perspectiva dos estudos focalizados exclusivamente na ação do professortutor evidencia que a mediação pedagógica pressupõe orientar, articular, instigar e construir o diálogo entre os participantes com vistas à construção ativa do conhecimento (Prado; Martins, 2001; Santos; Rezende, 2002; Cruz, 2010). Rios, Pimentel e Silva (2008) confirmam essa perspectiva ao ressaltar que o professormediador deve procurar a autoria e coautoria dos estudantes para que a construção do conhecimento aconteça. Machado e Teruya (2009) corroboram com a reflexão em torno da ação do professor-tutor no processo de mediação pedagógica ao demonstrarem que esta se efetiva com o ato de instigar a participação e o acompanhamento permanente dos estudantes ao longo do curso.

A segunda perspectiva combina técnica e pedagogia como elementos da mediação pedagógica. Os estudos de Alberto Sobrinho (2003), Prado (2006), Mallmann (2010), Mallmann e Catapan (2010) trazem significativas reflexões sobre a articulação entre os dispositivos técnicos e a necessária mediação técnicopedagógica a ser realizada em cursos a distância, para assegurar o processo de ensino-aprendizagem. Salienta-se a reflexão de Prado (2006) ao avaliar os materiais, assim como as atividades e as interações, como basilares para a mediação pedagógica de qualidade nos cursos virtuais. Com este mesmo ponto de vista, sobressaem-se os estudos de Mallmann (2010) e Mallmann e Catapan (2010), que dão destaque aos materiais didáticos e ao desempenho do professor na modalidade de educação a distância. Os referidos estudos assinalam o caráter mediador dos materiais didáticos por provocarem abstrações e construções dos conhecimentos, além de proporcionarem os essenciais encontros entre professores, estudantes e conhecimentos. Ainda sobre a segunda perspectiva, é oportuno salientar que Mallmann e Catapan (2010) enfatizam que a mediação pedagógica em cursos a distância deve relacionar interação e interatividade; portanto, pedagogia e tecnologia se realizam por intermédio dos artefatos didáticopedagógicos.

Em termos teóricos, cabe aqui destacar que a concepção de mediação mencionada nos trabalhos abordados evidencia, em parte, a distinção feita por Belloni (2001) entre interatividade e interação, na medida em que explicita que a mediação pedagógica não se consubstancia sem um desvelo entre os sujeitos do ato educativo, professor/tutor e estudante, em suas intersubjetividades; isto é, enquanto encontro entre sujeitos que se constitui, conceitualmente, na interação. Já a interatividade, enquanto característica técnica, se dá na possibilidade de o usuário interagir com uma máquina. 
Observou-se também que, nos artigos em tela, há uma diversidade de referenciais teóricos utilizados quanto ao que se compreende por mediação pedagógica. Todavia, há uma confluência de sentido quanto a entendê-la como a atitude, o comportamento flexível dos docentes ou tutores como facilitador, incentivador e motivador da aprendizagem do estudante, bem como uma perspectiva ativa frente à produção do conhecimento, tanto por parte do professor, quanto do estudante, conforme Masetto. (2008)

As distintas pesquisas apresentadas compreendem que a mediação pedagógica viabiliza a aprendizagem discente, sendo que o professor-tutor possibilita uma ação significativa entre os estudantes e o objeto do conhecimento a ser apreendido.

No Quadro 2 a seguir, são apresentadas as produções de mestrado e doutorado que, em seus títulos, tratam da mediação pedagógica na EaD. A pesquisa identificou um total de 16 (dezesseis) trabalhos: 1 (um) mestrado profissional, 8 (oito) mestrados acadêmicos e 7 (sete) pesquisas em nível de doutorado. 0 período considerado para a pesquisa foi de 2001 a 2011.

Quadro 2: Produções de mestrado e doutorado sobre mediação pedagógica

\begin{tabular}{|l|l|l|l|}
\hline \multicolumn{1}{|c|}{ Título } & Ano & Tipo & Universidade \\
\hline $\begin{array}{l}\text { Mediação do professor na interação } \\
\text { do aprendiz com o material didático } \\
\text { em contextos pedagógicos distintos: } \\
\text { o presencial e o virtual }\end{array}$ & 2001 & Mestrado & IEL/Unicamp \\
\hline $\begin{array}{l}\text { Interatividade e mediação } \\
\text { pedagógica na educação a distância }\end{array}$ & 2002 & Doutorado & $\begin{array}{l}\text { PUC/RS } \\
\text { - Educação }\end{array}$ \\
\hline $\begin{array}{l}\text { A mediação pedagógica e o uso dos } \\
\text { ambientes virtuais de aprendizagem } \\
\text { na educação presencial }\end{array}$ & 2006 & Mestrado & Cefet/MINAS \\
\hline $\begin{array}{l}\text { Mediações na formação a distância } \\
\text { de professores: autonomia, } \\
\text { comunicação e prática pedagógica }\end{array}$ & 2006 & Doutorado & $\begin{array}{l}\text { UFBA - } \\
\text { Educação }\end{array}$ \\
\hline $\begin{array}{l}\text { Mediação na Tutoria Online: o } \\
\text { entrelace que confere significado à } \\
\text { aprendizagem }\end{array}$ & 2007 & Mestrado & UFC/Unopar \\
\hline $\begin{array}{l}\text { A mediação pedagógica em } \\
\text { contextos de aprendizagem online }\end{array}$ & 2007 & Doutorado & PUC/SP \\
\hline $\begin{array}{l}\text { Chats e e-fóruns da EaD virtual: } \\
\text { links entre mediação pedagógica e } \\
\text { hipertextualidade }\end{array}$ & 2008 & $\begin{array}{l}\text { Mestrado } \\
\text { Departamento } \\
\text { de Letras }\end{array}$ \\
\hline
\end{tabular}




\begin{tabular}{|c|c|c|c|}
\hline $\begin{array}{l}\text { Mediação pedagógica em educação } \\
\text { a distância: cartografia da } \\
\text { performance docente no processo } \\
\text { de elaboração de materiais didáticos }\end{array}$ & 2008 & Doutorado & $\begin{array}{l}\text { UFSC - } \\
\text { Educação }\end{array}$ \\
\hline $\begin{array}{l}\text { A mediação pedagógica no ambien- } \\
\text { te virtual de aprendizagem Moodle: } \\
\text { um estudo no curso de Pedagogia a } \\
\text { distância do CE/UFPB Virtual }\end{array}$ & 2009 & Mestrado & UFPB \\
\hline $\begin{array}{l}\text { Mediação pedagógica em ambientes } \\
\text { virtuais de aprendizagem a partir } \\
\text { da complexidade e do pensamento } \\
\text { ecossistêmico }\end{array}$ & 2009 & Mestrado & UCB/Educação \\
\hline $\begin{array}{l}\text { Mediação pedagógica em ambientes } \\
\text { virtuais de aprendizagem }\end{array}$ & 2009 & Mestrado & $\begin{array}{l}\text { Universidade } \\
\text { Estadual } \\
\text { de Maringá } \\
\text { - Educação }\end{array}$ \\
\hline $\begin{array}{l}\text { Mediação pedagógica em EaD: a } \\
\text { falta de tempo como sintoma }\end{array}$ & 2009 & Doutorado & $\begin{array}{r}\text { PUC/SP } \\
\text { - Educação } \\
\end{array}$ \\
\hline $\begin{array}{l}\text { Mediação pedagógica na educação } \\
\text { distância: possibilidades a partir } \\
\text { das contribuições da abordagem de } \\
\text { Reuven Feuerstein }\end{array}$ & 2010 & Mestrado & UFU/Psicologia \\
\hline $\begin{array}{l}\text { A mediação pedagógica na educação } \\
\text { teológica a distância: um estudo de } \\
\text { caso }\end{array}$ & 2010 & Doutorado & $\begin{array}{l}\text { Escola Supe- } \\
\text { rior de Teologia } \\
\text { - São Leopol- } \\
\text { do/RS }\end{array}$ \\
\hline $\begin{array}{l}\text { Educação online em metaverso: a } \\
\text { mediação pedagógica por meio da } \\
\text { telepresença e da presença digital } \\
\text { virtual via avatar em mundos digitais } \\
\text { virtuais em três dimensões }\end{array}$ & 2010 & Mestrado & $\begin{array}{l}\text { Unisinos/Edu- } \\
\text { cação }\end{array}$ \\
\hline $\begin{array}{l}\text { O belo na mediação pedagógica: as } \\
\text { especificidades desta relação em } \\
\text { ambientes virtuais de aprendizagem }\end{array}$ & 2011 & Doutorado & $\begin{array}{l}\text { PUC/SP - Edu- } \\
\text { cação }\end{array}$ \\
\hline
\end{tabular}

Fonte: Quadro elaborado pelos autores com base na Biblioteca Digital Brasileira de Teses e Dissertações (BDTD) 
A apresentação das dissertações sobre a temática em pauta dará prioridade aos estudos que incrementam a reflexão produzida pelos artigos já apresentados, os quais indicaram duas perspectivas que se complementam sobre a mediação pedagógica, que são: o papel do professor-tutor e a articulação entre a atuação do professor e os artefatos tecnológicos.

Inicialmente, destaca-se a pesquisa de doutorado de Faria (2002), que procurou conhecer como a interatividade e a mediação são concebidas e realizadas nos ambientes virtuais de aprendizagem com vistas à criação de propostas para melhorar o ensino e a aprendizagem. 0 ponto forte do estudo são os sujeitos pesquisados, que foram tanto professores quanto estudantes de um curso de pós-graduação lato sensu. A pesquisadora enfatiza que o ambiente virtual tem amplas possibilidades de desenvolver o diálogo, as trocas e escutas em função da comunicação síncrona e assíncrona. Porém, a partir das verbalizações dos estudantes, ela constatou que os recursos disponíveis não são suficientes para que a mediação ocorra; faz-se necessário, portanto, a presença ativa do professor, que precisa planejar e realizar de forma intencional a mediação pedagógica. A relevância deste estudo está no entendimento da necessidade de uma ação intencional do professor com a finalidade de utilizar adequadamente os espaços de interação para a aprendizagem dos estudantes. Logo, em cursos virtuais, a mediação da aprendizagem exige que o professor organize o ambiente, os materiais e utilize estratégias que provoquem os estudantes socioindividualmente.

Andrade (2007), em sua dissertação de mestrado, buscou compreender as dimensões do trabalho do tutor em processos educativos a distância e a interface do seu trabalho no processo de ensino-aprendizagem. A pesquisa, que foi realizada por meio de aplicação de um questionário com tutores, descreveu as atribuições relacionadas aos papéis e responsabilidades do tutor e identificou uma ação mediadora na prática deste profissional. Com isto, a pesquisa se propôs a elaborar uma tipologia baseada na Experiência de Aprendizagem Mediada em relações educativas a distância. Tal tipologia considera que, no trabalho de acompanhamento da aprendizagem, o tutor realiza mediação produzindo ênfases, selecionando, aprimorando e conferindo complexidades às tarefas desenvolvidas. Assim, o tutor deve buscar dinamizar o grupo, por meio de perguntas, e observar as respostas e silêncios para que possa acompanhar e potencializar as necessidades do grupo e produzir um retorno intencional.

0 estudo de Gervai (2007) objetivou analisar e descrever os tipos de mediação on-line em trabalhos individuais dos estudantes e nos fóruns de discussão em um curso sobre práticas de leitura e escrita. Os resultados revelaram que a mediação docente possibilita reduzida oportunidade de maior engajamento dos estudantes no processo de aprendizagem, apesar de as tecnologias proporcionarem condições para a realização de trocas e construção coletiva do conhecimento. 0 estudo destaca ainda que, a depender da mediação pedagógica, é possível acontecer, 
ou não, uma maior aprendizagem dos estudantes. Assim, a função do professortutor de intervir e suscitar a participação e a troca entre os estudantes tornase indispensável em cursos a distância. A pesquisa mostra ainda a necessidade de o professor realizar uma mediação que problematize as questões trazidas pelos estudantes na interação. Este movimento docente promove troca de conhecimentos e maior engajamento na aprendizagem por parte dos estudantes. Por fim, o estudo é assertivo ao constatar que, do mesmo modo que precisa saber lidar com a mediação presencial, o docente precisa aprender a fazer mediação em ambientes virtuais de aprendizagem.

Silva (2008) investigou, a partir das perspectivas bakhtiniana e vygostkyana sobre interação e mediação, a influência da natureza hipertextual dos gêneros digitais chats e e-fóruns educacionais na mediação pedagógica e na interação de cursos a distância realizados pela internet. A pesquisa identificou que o uso dos recursos hipertextuais por estudantes e tutores é diversificado. Constataram-se utilizações como: curiosidade, preocupação, satisfação, incentivo, compartilhamento de informações, surpresa, entusiasmo, entre outras formas. Com efeito, o estudo demonstrou que os professores conseguiram dinamizar a mediação pedagógica, e os estudantes, do mesmo modo, utilizaram os recursos para dirimirem dúvidas e realizarem trocas de informações. Por fim, o estudo concluiu que a ferramenta digital é uma via de mão dupla, em que professores e estudantes podem aprender de forma coletiva.

Machado (2009) analisou, em sua dissertação de mestrado, a mediação pedagógica no ambiente virtual em um curso de formação de professores. A autora observou as ações de tutores e alunos ao longo do curso. Os resultados indicaram que os pesquisados consideram que a mediação pedagógica no ambiente virtual é importante para o processo de aprendizagem. Compreendem que a mediação diz respeito à interação com o meio, com as pessoas, com os signos, com a linguagem falada e escrita. Para a concretização da mediação, destacam a presença permanente do tutor nos espaços de interação como fundamental para a efetivação do aprendizado. Ademais, a pesquisa revela que a mediação é feita, primeiramente, pelo tutor e que os recursos de interação são as ferramentas que viabilizam a ação dos tutores. Com efeito, a mediação pedagógica pressupõe estratégias pedagógicas diferenciadas das usadas na educação presencial, mas que deve ocorrer tendo como referência as relações interpessoais e a interação mútua dos participantes da formação.

0 foco da dissertação de mestrado de Schechtman (2009) foi a mediação pedagógica em ambientes virtuais de aprendizagem, a partir da complexidade e do pensamento ecossistêmico. 0 estudo analisou o projeto e o planejamento de um curso, as interações nos espaços de comunicação do ambiente virtual de aprendizagem e o material didático como forma de destacar a mediação pedagógica nos espaços de comunicação. A contribuição deste estudo para a mediação pedagógica em cursos a distância está na indicação da importância 
de o aprendiz, na educação a distância, ter atitudes, habilidades e competências para desenvolver o seu potencial nesta modalidade de ensino. A autora salienta que, se o estudante em cursos de EaD não tiver acesso fácil à internet, tempo para se dedicar aos estudos e experiência com as ferramentas de comunicação, a mediação pedagógica torna-se prejudicada. Diante disso, a autora considera que a mediação pedagógica não pode ser vista como uma ação isolada que corrigirá todas as distorções do sistema. Portanto, o sistema em EaD, para favorecer a mediação pedagógica, deve articular com clareza o planejamento e a formação dos envolvidos no processo de ensino-aprendizagem para que esta seja eficaz e possa lidar com as incertezas e emergências do processo de estudar na modalidade a distância.

O doutoramento de Espírito Santo (2010) analisou a mediação pedagógica em três ferramentas de um ambiente virtual: webAulas (textos em pdf), videoaulas e atividades de aprendizagem em um curso de teologia. Os resultados do estudo indicam que há uma transposição da forma de ensinar presencial para a modalidade a distância; os videoaulas reproduzem a aula presencial; os textos das webAulas são feitos como textos acadêmicos; as atividades de aprendizagem são, na sua maioria, atividades de apropriação de conhecimentos. Assim, o autor salienta que é necessário construir uma arquitetura pedagógica, em que os conteúdos das webAulas e das videoaulas favoreçam a autoaprendizagem, e que as atividades devem possibilitar a interaprendizagem, na qual ocorra a relação texto-contexto e de aplicabilidade. Por fim, a conclusão da pesquisa indicou a necessidade de que os cursos a distância não fiquem tão somente na mediação tecnológica, mas que consigam construir uma sólida e bem planejada mediação pedagógica.

Pires (2010), em sua dissertação de mestrado, buscou compreender como a (re)criação de identidades digitais virtuais para interações em mundos digitais contribui para a falta de presença física do professor na educação on-line, com processos de mediação pedagógica mais responsáveis. 0 estudo revelou que utilizar avatares potencializa uma melhor comunicação entre estudantes e professores. No entanto, faz-se necessário formação técnica e pedagógica do professor para lidar com essas tecnologias. Além de conhecer o que o ambiente virtual disponibiliza, o professor necessita saber utilizar as tecnologias para que potencialize o seu uso. A falta de formação técnica subutiliza a tecnologia e a torna repositório de conteúdos. Do mesmo modo, sem a formação pedagógica, as ações de mediação não apresentam significado para os sujeitos aprendentes.

Moraes (2011), na sua tese de doutorado, buscou compreender o belo como uma categoria da mediação pedagógica feita pelo professor em ambientes virtuais de aprendizagem. A pesquisa utilizou-se da análise documental dos registros gerados no ambiente virtual de aprendizagem, além de entrevistas com os formadores do curso de aperfeiçoamento. A pesquisa ensina que o belo foi percebido na harmonia da mediação pedagógica, especialmente na atuação dos formadores. A autora compreende que a harmonia é o belo que está presente na mediação pedagógica, 
que considera o outro, a sua história e constitui um diferencial no processo formativo. Desse modo, é a atuação do formador que possibilita o processo de mediação flexível, com autonomia e autoria que produz a harmonia e constrói o belo.

As dissertações supracitadas confirmam as perspectivas de mediação pedagógica em cursos a distância destacadas nos artigos apresentados no Quadro 1, quais sejam: o lugar do tutor no processo de mediação e a necessidade de articular a ação do professor com as tecnologias. Além disso, percebe-se que as pesquisas de mestrado e doutorado evidenciadas produzem reflexões que podem potencializar os processos de mediação pedagógica nas diversas instituições que ofertam programas na modalidade de educação a distância. Considere-se que, em sua maioria, os elementos didático-pedagógicos do planejamento da mediação e a necessária formação dos professores para atuarem como mediadores foram presentes nas pesquisas salientadas.

Observa-se nos estudos de Faria (2002), Schechtman (2009) e Espírito Santo (2010) indicações quanto à necessidade de se realizar um planejamento sólido da mediação pedagógica, em que a ação intencional do professor quanto ao uso apropriado dos espaços de interação, com vistas à aprendizagem dos estudantes, faça parte da prática docente nos contextos de ensino mediados por tecnologias da informação e comunicação. Uma mediação pedagógica planejada pode, efetivamente, minimizar o vazio que ocorre entre o potencial das tecnologias e a ação docente em processos de ensino e aprendizagem mediados pelas novas tecnologias (Demo, 2011). O planejamento como um processo dinâmico de reflexão e ação que visa prever toda a dinâmica do ensino para que a aprendizagem seja efetiva e melhor para os estudantes (Vasconcellos, 1995), na educação a distância, apresenta-se como imprescindível para a qualidade dos processos de ensinoaprendizagem, vista a especificidade da relação pedagógica não ocorrer face a face.

Outro ponto de destaque nos estudos citados diz respeito à formação dos professores para realizarem uma prática mediadora. Nota-se que saber utilizar as tecnologias (dimensão técnica) para que estas não sejam subutilizadas, juntamente com um saber pedagógico para que a mediação tenha significado para os estudantes, é necessário para uma mediação pedagógica que saiba lidar com o imprevisível do contexto educacional, visando ao desenvolvimento da autoria e do espírito crítico, finalidades necessárias para uma educação que se quer não reprodutiva, mas crítica e criativa. (Schechtman, 2009; Pires, 2010; Moraes, 2011)

Desse modo, a mediação pedagógica pesquisada e pensada nos estudos aqui apresentados envolve um ciclo de planejamento e formação docente continuada para que a ação do professor consiga articular os dispositivos técnicos e pedagógicos com vistas a fortalecer uma prática capaz de orientar, tramar, problematizar, instigar e mobilizar o diálogo para uma produção do conhecimento de forma ativa. 
Salienta-se que a concepção de mediação pedagógica destacada nos diversos estudos se aproxima da abordagem histórico-cultural ao compreenderem que o papel do docente, ou seja, do professor-tutor, é o de viabilizar a aprendizagem do estudante considerando-o como um sujeito com potencial, constitutivo de história e de cultura.

\section{Considerações finais}

As referências citadas nos Quadros 1 e 2 são, certamente, apenas uma parte da ampla reflexão que vem sendo feita nas pesquisas em educação a distância com o foco na mediação pedagógica. Identifica-se que os diversos estudos destacados assumem uma perspectiva comum voltada para a presença constante e problematizadora do professor nos ambientes virtuais de aprendizagem. Isso demonstra o papel central do professor na aprendizagem dos estudantes na modalidade de educação a distância, em que a mediação pedagógica é tida como um elemento básico para a qualidade dos sistemas educativos que se utilizam de tecnologias para a realização do processo de ensino e aprendizagem.

Assevera-se que todos os pontos manifestados pelos estudos como fundamentais para um processo de qualidade da mediação pedagógica, como o planejamento, a formação dos professores, os materiais didáticos, as atividades e os dispositivos tecnológicos, compõem a arquitetura de cursos a distância que se direcionem para realizar uma educação focalizada na aprendizagem crítica e criativa, tão necessária para o desenvolvimento do País. 0 modelo de mediação pedagógica em EaD que corresponda a tal realidade, isto é, de uma aprendizagem crítica e criativa, que enseje uma educação emancipadora deve priorizar a coparticipação do estudante no processo de construção do conhecimento. Sem isso, o modelo perfilador da mediação pedagógica continuará sendo o que, mesmo se servindo de um sofisticado aparato tecnológico, reproduz as relações autoritárias da sociedade e, sobretudo, desconsidera o papel ativo do discente na construção do conhecimento.

Vale lembrar que entender o significado da mediação pedagógica é também uma tarefa política, pois todo ato educativo é um ato político, como bem ressalta Freire (2005). A mediação pedagógica em EaD deve ser fruto de um processo de reflexão, com base em um aprendizado sobre o pensar crítico da própria prática docente. Agindo assim, o docente contribuirá para superar o amadorismo, um fazer automatizado ou regido por interesses que destituem a autonomia do ato educativo e usurpam a interatividade produtora de subjetividades e alteridades que devem plasmar as relações, ou sociações, na perspectiva simmeliana, entre os docentes, os discentes e as tecnologias.

A interação e interatividade entre os estudantes, os conteúdos e os professores 
se constituem um dos principais resultados da mediação pedagógica. Esta, somada ao uso de tecnologias regidas por uma intencionalidade político-pedagógica emancipadora de caráter colaborativo e democratizante, confirma a possibilidade do uso da tecnologia, especialmente na educação, como meio potencializador de práticas pedagógicas, quiçá em conformidade com a intencionalidade acima apresentada.

Enfim, os vários estudos realizados por pesquisadores brasileiros não apenas ressaltam a importância da mediação pedagógica nos processos de educação a distância, mas apontam elementos didático-pedagógicos que precisam ser efetivamente inseridos pelos diversos sistemas de EaD. Nesse sentido, cabe assegurar com maior relevância práticas consistentes de mediação pedagógica em que a ação docente mobilize a capacidade do estudante de aprender a aprender.

\section{Referências}

ALBUQUERQUE JÚNIOR, Álvaro George Rosas de. Amediaçãopedagógica noambiente virtual de aprendizagem Moodle: um estudo no curso de pedagogia a distância do CE/UFPB VIRTUAL. Dissertação (Mestrado em Educação) - Universidade Federal da Paraíba, João Pessoa, 2009. 165p.

AMARAL, Mara Márcia Richard Ávila. A mediação pedagógica e o uso dos ambientes virtuais de aprendizagem na educação presencial. Dissertação (Mestrado em Educação Tecnológical - Centro de Educação e Tecnologia de Minas Gerais, 2006. $147 \mathrm{p}$.

ANDRADE, Jaqueline Barbosa Ferraz de. Mediação na tutoria online: o entrelace que confere significado à aprendizagem. Dissertação (Mestrado em Tecnologia da Informação e Comunicação na Formação em Educação a Distâncial - UFC/ UNOPAR, Salvador, 2007. 95p.

BELLONI, Maria Luiza. Educação a distância. Campinas: Autores Associados, 2001.

COSTA, Lúcia Alves. A mediação do professor na interação do aprendiz com o material didático em contextos pedagógicos distintos: o presencial e o virtual. Dissertação (Mestrado em Linguística Aplicada) - Universidade Estadual de Campinas UNICAMP/IEL, Campinas 2001. 175 p.

CRUZ, Márcia Dulce. Formação docente e mediação pedagógica em cursos de licenciatura a distância do sistema universidade aberta do Brasil. Inter Ação, Revista da Faculdade de Educação da UFG, v. 35, n. 2, pp. 323-340. 2010.

ESPÍRITO SANTO, Eliseu Roque do. A mediação pedagógica na educação teológica a distância: um estudo de caso. Tese de Doutorado. São Leopoldo: EST/PPG, 2010. $237 \mathrm{p}$.

FARIA, Elaine Turk. Interatividade e mediação pedagógica na educação a distância. 
Tese (Doutorado em Educação) - Faculdade de Educação PUCRS, Porto Alegre, 2002. 214 p.

FERREIRA, Juliene Madureira. Mediação pedagógica na educação a distância: possibilidades a partir das contribuições da abordagem de Reuven Feuerstein. Dissertação de Mestrado, Uberlândia: UFU/Psicologia, 2010.

FREIRE, Paulo. Pedagogia do oprimido. 43. ed. Rio de Janeiro: Paz e Terra, 2005.

GERVAl, Solange Maria Sanches. A mediação pedagógica em contextos de aprendizagem online. Tese (Doutorado em Linguística Aplicada e Estudos da Linguagem) - PUC/SP, Programa de Estudos de Pós-Graduados em Linguística Aplicada e Estudos da Linguagem, São Paulo, 2007. 249 p.

MACHADO, Suelen Fernanda; TERUYA, Teresa Kazuko. Mediação pedagógica em ambientes virtuais de aprendizagem: a perspectiva dos alunos. In: IX Congresso Nacional de Educação - EDUCERE. III Encontro Sul Brasileiro de Psicopedagogia. 2009. p. 1726-1738. Disponível em: <http://nt5.net.br/publicacoes/mediacao_Suelem_ Teresa.pdf>. Acesso em: 20 set. 2012.

MACHADO, Suelen Fernanda. Mediação pedagógica em ambientes virtuais de aprendizagem. Dissertação (Mestrado em Educação) - Universidade Estadual de Maringá, 2009.

MALLMANN, Elena Maria. Mediação pedagógica em educação a distância: cartografia da performance docente no processo de elaboração de materiais didáticos. Tese (Doutorado em Educação) - Universidade Federal de Santa Catarina/Programa de Pós-Graduação em Educação, Florianópolis/SC, 2008. 304p.

Mediação pedagógica em educação a distância: inovação na docência universitária no processo de elaboração de materiais didáticos. RIED. Revista Iberoamericana de Educación a Distancia,v. 12, n.1, pp. 157-189, 2010.

MALLMANN, Elena Maria; CATAPAN, Araci Hack. Performance docente na mediação pedagógica em educação a distância. Inter Ação, Revista da Faculdade de Educação da UFG, v. 35, n. 2, pp. 341-358, 2010.

MASETTO, T. Marcos. Mediação pedagógica e o uso da tecnologia. In: MORAN, José Manuel; MASETTO, T. Marcos; BEHRENS, Marilda Aparecida. Novas tecnologias e mediação pedagógica. 14a. ed. Campinas, SP: Papirus, 2008.

MORAES, Maria Beatriz Villas Boas de. Educação online em metaverso: a mediação pedagógica por meio da telepresença e da presença digital virtual via avatar em mundos digitais virtuais em 3 dimensões. Tese (Doutorado) - Pontifícia Universidade Católica de São Paulo- PUC/SP, São Paulo, 2011. 164 p.

PIRES, Daiana Trein. Educação online em metaverso: a mediação pedagógica por meio da telepresença e da presença digital virtual via avatar em mundos digitais virtuais em 3 dimensões. Dissertação (Mestrado em Educação) - Universidade do Vale do Rio Sinos - UNISINOS, São Leopoldo, 2010. 224p.

PRADO, Maria Elisabete Brisola Brito; MARTINS, Maria Cecília. A mediação pedagógica em propostas de formação continuada de professores em informática na educação. In: VIII Congresso Internacional de Educação a Distância da ABED. 
Brasília, DF, 2001. Publicado no portal:<http://www.abed.org.br>. Acesso em: 19 set. 2012.

PRADO, Maria Elisabete Brisola Brito. A mediação pedagógica: suas relações e interdependências. In: Anais do XVII Simpósio Brasileiro de Informática na Educação. Brasília, 2006.

RANGEL, Flaminio de Oliveira. Mediação pedagógica em EAD: a falta de tempo como sintoma. Tese (Doutorado) - Pontifícia Universidade Católica de São Paulo, São Paulo, 2009. 210p.

RIOS, Almeida Jocelma; PIMENTEL, Renê Gomes; SILVA, Bento Duarte. Mediação pedagógica online: análise transversal de ferramentas de interação. In: Colóquio Luso-Brasileiro sobre questões curriculares 4. Florianópolis: Universidade Federal de Santa Catarina (UFSC), 2008, p. 19. Disponível em: <http://repositorium.sdum. uminho.pt/bitstream/1822/10036/1/MEDIA\%C3\%87\%C3\%830\%20PEDAG\%C3\%9 3GICA\%200NLINE\%20AN\%C3\%81 LISE\%20TRANSVERSAL\%20DE\%20FERRAME NTAS\%20DE\%20INTERA\%C3\%87\%C3\%830.pdf>. Acesso em:17 set. 2012.

RODRIGUES, Cleide Aparecida Carvalho. Mediações na formação a distância de professores: autonomia, comunicação e prática pedagógica. Tese (Doutorado) - Faculdade de Educação - UFBA, Salvador, BA, 2006.

SANTOS, Henriete; REZENDE, Flávia. Formação, mediação e prática pedagógica do tutor orientador em ambientes virtuais construtivistas de aprendizagem. Tecnologia Educacional, v. 31, n. 157/158,p.19-29, abr.-set. 2008.

SCHECHTMAN, Sheila. Mediação pedagógica em ambientes virtuais de aprendizagem a partir da complexidade e do pensamento ecossistêmico. Dissertação (Mestrado) - Universidade Católica de Brasília, Brasília, 2009.

SILVA, Francisca Monica. Chats e e-fóruns na EAD virtual: links entre mediação pedagógica e hipertextualidade. Dissertação (Mestrado) - Universidade Federal do Ceará, Fortaleza/CE, 2008. 195p.

SIMMEL, Georg. Questões fundamentais da sociologia: indivíduo e sociedade. Rio de Janeiro: Jorge Zahar, 2006.

ALBERTO SOBRINHO, Carlos Mediação digital e pedagógica. Revista Teias, Universidade do Estado do Rio de Janeiro, ano 4, n. 7-8, jan./dez. 2003. Disponível em:<http://www.revistateias.proped.pro.br/index.php/revistateias/article/ view/220/220>. Acesso em: 20 set. 2012.

SOUSA, Carlos Ângelo de Meneses. Novas Linguagens e Sociabilidades: como uma juventude vê novas tecnologias. Revista Interacções. Santarém, Portugal, v. 7, no 17, p. 170-188. 2011. Disponível em: <http://revistas.rcaap.pt/interaccoes/ article/view/452/406>. Acesso em: 20 fev. 2013.

VASCONCELLOS, Celso dos Santos. Planejamento: plano de ensino-aprendizagem e projeto educativo. São Paulo: Libertad, 1995.

VYGOTSKY, Liev S. A formação social da mente: o desenvolvimento dos processos psicológicos superiores. 5 ed. São Paulo: Martins Fontes, 1994. 
Recebido em fevereiro de 2013

Aprovado em julho de 2013

Carlos Ângelo de Meneses Sousa é doutor em Sociologia pela Universidade de Brasília - UnB, professor do Programa de Pós-graduação em Educação da Universidade Católica de Brasília - UCB. E-mail: cangeloducb.br ; cangelosquol. com.br

Lêda Gonçalves de Freitas é doutora em Psicologia Social pela Universidade de Brasília - UnB, professora do Programa de Pós-graduação em Psicologia da Universidade Católica de Brasília - UCB. E-mail: ledagQuucb.br 